\title{
Should penile rehabilitation become the norm following radical prostatectomy?
}

\author{
Tariq Al Shaiji, MB ChB, FRCSC; Gerald Brock, MD, FRCSC
}

\section{Introduction}

Few areas of medicine, let alone urology, are as controversial as the question of whether postprostatectomy penile rehabilitation has a place in current therapeutics. There are 3 essential elements that must be evaluated in this debate: 1) Do sexual and erectile dysfunctions (EDs) exert a meaningful impact on quality of life for couples following radical prostatectomy (RP)? 2) Is there credible, reproducible and objective evidence that the proposed interventions improve functional results for patients and partners to a significant degree? 3) Is there a risk or down side to initiating rehabilitative strategies in the affected population?

The past decade has been witness to improved surgical techniques coupled with widespread adoption of laparoscopic and robotic approaches for prostatectomy. Nerve-sparing radical prostatectomy (NSRP) is now widely employed and believed to improve postoperative erectile function. ${ }^{1}$ However, complete erectile recovery may take up to 24 months, and even among men in whom bilateral nerve-sparing techniques are performed, the recovery rate varies from $16 \%$ to $86 \% .^{2-4}$ In the current era of early detection driven by prostate cancer screening programs and widespread prostatespecific antigen testing, many young, sexually active men are undergoing surgery. In this population, preservation of erectile function after the procedure is paramount. In 2003, Penson and Litwin ${ }^{5}$ reported that sexual dysfunction was the most important quality-of-life issue at 24 months from the time of primary prostate cancer treatment. The negative impact of sexual bother on quality of life and self-esteem appears to be proportional to time from intervention, meaning it has a greater impact with time. In addition, it has been documented that nervesparing techniques alone do not seem to be sufficient to prevent sexual impairment. ${ }^{3}$ Recent insights into the pathophysiology of postprostatectomy ED have stimulated great attention toward the concept of penile rehabilitation, also known as erectile function preservation programs, in which prophylactic measures are instituted to promote early recovery from ED. Nevertheless, the concept of penile rehabilitation continues to generate active discussions among treating physicians.

\section{Pathophysiology of postprostatecto- my erectile dysfunction}

Although the exact underlying etiology of sexual dysfunction following prostate cancer therapy remains to be fully elucidated, there are several key elements that clinicians and patients need to deal with: ED as a consequence of nerve and arterial vascular injury, penile fibrosis resulting in length and girth loss, and veno-occlusive dysfunction-induced ED.

Following NSRP, spontaneous erectile function is frequently impaired, thought to be secondary to reversible injury of the cavernous nerves, a process known as neurapraxia. This temporary deficit of the cavernosal nerves can abolish any form of erection and has a time course lasting up to several years. Neurapraxia is believed to be caused by a combination of mechanical, thermal, ischemic and local inflammatory effects associated with surgical trauma, and occurs even in the hands of the most experienced surgeons. ${ }^{6,7}$ 
Normal cavernosal smooth muscle content and function are essential for the initiation and maintenance of erection and their integrity is dependent on tissue oxygenation, which modulates nitric oxide synthesis. Presently, the predominant theory of RP-induced ED is that as a result of neurapraxia, an environment of persistently low oxygen tension exists in a constantly flaccid penis often initiating severe fibrotic changes within the cavernosal tissue. In an experimental model by Leungwattanakij and colleagues, ${ }^{8}$ penile tissue from rats that had undergone bilateral injury of the cavernosal nerves 3 months earlier, showed a significant overexpression of hypoxia-related cytokines like transforming growth factor- $\beta$ (TGF$\beta 1$ ) with increased amounts of collagen I and III, compared with controls. Daley and coauthors ${ }^{9}$ reported that the production of prostaglandin E1 was decreased in the cavernosal muscle, which has been previously shown to suppress the TGF$\beta 1$-induced collagen accumulation and is also oxygen dependent. Similarly, User and coauthors ${ }^{10}$ performed bilateral neurotomy of the rat penis and found that there was a significant increase in apoptosis in the subalbugineal smooth muscle cells. This loss of smooth muscle beneath the tunica leads to venous leak and is evident clinically as venogenic ED. ${ }^{11}$ Mulhall and coworkers ${ }^{12}$ have shown that the longer the patient waits after surgery before initiating erectile function, the more likely it is that venous leak will develop, implying underlying corporal smooth muscle fibrosis. Finally, penile shortening is frequently reported by patients and partners following RP and believed to be a result of corporal fibrosis, increased apoptosis and de novo Peyronie disease formation. ${ }^{13}$

\section{Evidence in support of penile rehabilitation}

Penile rehabilitation has recently been described as the application of any drug or device at or after RP to speed up recovery of erectile function. ${ }^{14}$ Most current strategies directed at penile rehabilitation seek to improve cavernosal oxygenation, promote endothelial protection and prevent structural changes within the penis caused by nerve injury. Both animal and human models have been described supporting the concept of penile rehabilitation.

It has been shown that animals exposed to bilateral cavernous neurotomy treated with phosphodiesterase type 5 (PDE5) inhibitors compared with placebo controls have significant preservation of erectile function and cavernosal smooth muscle content. This was demonstrated in rat models by Mulhall and coauthors ${ }^{15}$ using sildenafil, Ferrini and colleagues ${ }^{16}$ using vardenafil and Vignozzi and coworkers ${ }^{17}$ using tadalafil. The protective nature of these agents appears to be a class effect, with evidence showing robust measurable improvements in smooth muscle and erectile function with both short- and long-acting drugs. In another study, Kovanecz and colleague ${ }^{18}$ showed that long-term continuous sildenafil resulted in improvement of venous leak following cavernous nerve resection. Using a diabetic rat model in our laboratory, De Young and colleagues ${ }^{19}$ demonstrated improved endothelial and smooth muscle protein expression and penile histological morphology with chronic vardenafil use, compared with controls. These data demonstrate the ability of PDE5 inhibitors to be myoprotective and possibly myotrophic..$^{14}$ Finally, Muller and coauthors ${ }^{20}$ have observed preservation of erectile function when hyperbaric oxygen was applied to cavernous nerve-injured rats, supporting the role of cavernosal oxygenation.

The first landmark human study to demonstrate an advantage of early rehabilitation was performed by Montorsi and colleagues ${ }^{21}$ in a 1997 randomized controlled trial on patients who underwent bilateral NSRP. The authors showed that recovery of spontaneous erection occurred at 6 months in 8 of 12 patients who self-injected with prostaglandin-E, versus 3 of 15 who did not receive injections. Mulhall and colleagues ${ }^{22}$ followed up 132 patients in a prospective nonrandomized fashion after they were placed in "rehabilitation" or "no rehabilitation" groups after RP. Patients undergoing rehabilitation agreed to take sildenafil or intracavernosal alprostadil to induce erection 3 times weekly starting within the first 4 weeks after surgery. After 18 months of follow-up, $52 \%$ of the men in the rehabilitation protocol group reported spontaneous functional erections, compared with $19 \%$ of the men in the "no rehabilitation" group. Brock and colleague ${ }^{23}$ demonstrated that long-term intracavernosal self-injection of alprostadil improved penile circulation and led to a return of spontaneous erection in men with arteriogenic $\mathrm{ED}$, thus confirming a potential curative role of this therapeutic modality in selected patients.

A number of human clinical studies of PDE5 inhibitors exist in this population as well. Desouza 
and colleagues ${ }^{24}$ showed that the use of sildenafil at $25 \mathrm{mg}$ results in significant endothelial function improvement based on flow-mediated dilation (FMD) assessment in the acute ( $1 \mathrm{~h}$ after drug exposure) and chronic ( $14 \mathrm{~d}$ of treatment with FMD assessment $24 \mathrm{~h}$ after drug exposure) setting. Schwartz and colleagues ${ }^{25}$ conducted an important experiment which demonstrated that 6 months of sildenafil had the ability to arrest (at $50 \mathrm{mg} / \mathrm{d}$ ) or reverse (at $100 \mathrm{mg} / 2 \mathrm{~d}$ ) the loss of cavernosal smooth muscle postprostatectomy by comparing penile biopsies pre- and postoperatively. Padma-Nathan and coauthors ${ }^{26}$ published the first randomized placebo-controlled trial assessing the clinical utility of chronic PDE5 inhibitor use. Seventy-six men were randomized into 3 arms 4 weeks after an NSRP: 23 patients in the sildenafil $50 \mathrm{mg} /$ day arm, 28 patients in the sildenafil $100 \mathrm{mg} /$ day arm and 25 patients in the placebo arm. Patients took daily medication for 36 weeks and had an 8-week washout period. Twenty-seven percent of patients taking sildenafil ( 50 or $100 \mathrm{mg} / \mathrm{d}$ ) were able to achieve a natural erection versus $4 \%$ in the placebo group. ${ }^{27}$

Recently in a well-designed trial, Montorsi and colleagues ${ }^{28}$ compared on-demand and nightly dosing of vardenafil to placebo controls on the recovery of erectile function in postprostatectomy patients. This large, randomized, placebo-controlled, doubleblind, multicentre study evaluated vardenafil use in men with normal preoperative erectile function (International Index of Erectile Function, erectile function domain [IIEF-EF] score $\geq 26$ ) who had undergone an NSRP. Within 14 days of surgery, men were randomized into 3 study arms: placebo $(n=210)$, vardenafil $10 \mathrm{mg}$ nightly with on-demand placebo $(n=210)$ and nightly placebo with ondemand vardenafil $10 \mathrm{mg}(n=208)$. Treatment occurred over a 9-month period after which there was a single-blind placebo washout for 2 months and an additional 2 month open-label vardenafil on-demand period. After the double-blind treatment period, on-demand vardenafil was associated with significantly greater IIEF-EF scores $\geq 22$ compared with placebo $(p<0.001)$ and nightly vardenafil $(p=0.006)$. Additionally, the successful rates of the Sexual Encounter Profile (SEP3) question were statistically significant, in favour of on-demand vardenafil $(45.9 \%)$ compared with nightly vardenafil $(34.5 \%, p=0.011)$ and placebo $(25 \%, p<0.001)$.

Alternative strategies have been explored for the purposes of penile rehabilitation. Köhler and col- leagues ${ }^{29}$ recently performed a pilot study on the early use of the vacuum constriction devices after RP. Twenty-eight men undergoing RP were randomized to early intervention ( 1 mo after surgery, group 1) or a control group (6 mo after surgery, group 2) using a traditional vacuum constriction device. The IIEF scores were significantly higher in group 1 than group 2 at 3 and 6 months after surgery. Stretched penile length was significantly decreased at both 3 and 6 months, by about $2 \mathrm{~cm}$ in group 2. On the other hand, stretched penile length was preserved in group 1 at all sample times. Raina and colleagues reported their experience at the Cleveland Clinic with early post-NSRP intraurethral alprostadil in a prospective, nonrandomized study of 91 patients. ${ }^{30}$ Fifty-six received early intraurethral alprostadil, and 35 did not receive any early erectogenic treatment except for oral PDE5 inhibitors on an as-needed basis. Self-administration of medicated urethral system for erection (MUSE) was initiated about 3 weeks after RP. At a median followup of 6 months, $74 \%$ of the patients who remained on MUSE were able to regain erections sufficient for vaginal intercourse as opposed to $37 \%$ of the untreated control group. Finally, the use of combination therapy regimens has been studied with a promising result as shown by Marmar and colleagues, ${ }^{31}$ Yassin and Saad ${ }^{32}$ and Nandipati and

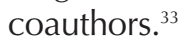

\section{Conclusion}

Recent discoveries have improved our understanding of the mechanism of postprostatectomy ED at molecular levels. The central role played by hypoxia and the cascade of events that it triggers leading to smooth muscle cell loss, fibrosis and quantifiable penile shape changes are clear. Erectile dysfunction following radical prostate cancer therapy significantly affects the quality of life of most patients and partners. Although definitive and conclusive evidence defining the specific protocol of penile rehabilitation does not currently exist, the overwhelming weight of basic animal and human trials support a protective role for PDE5 inhibitors in endothelial, smooth muscle and potentially nerve regenerative strategies in this population.

Although we acknowledge that barriers to such programs are cost and patient compliance, the time-sensitive nature of the irreversible cellular 
and structural changes that frequently occur argue against a watchful waiting approach in most situations where sexual preservation is important to the patient and partner. Obviously, large prospective, multicentred, placebo-controlled trials with adequate follow-up are needed to more fully define the optimal rehabilitative agent, dose, timing and target population. With these limitations in mind, if I had a prostatectomy today, I have no doubt that I would be starting my penile rehabilitation protocol tomorrow.

From the Division of Urology, Department of Surgery, University of Western Ontario, London, Ont.

The positions provided in the Point/Counterpoint series are presented as general information and do not necessarily reflect the personal opinions of the authors.

This article has been peer reviewed.

Competing interests: None declared for Tariq Al Shaiji. Gerald Brock is a consultant for, has participated in clinical trials with, is on the speakers board for and holds stock in Bayer, Pfizer, Lilly, American Medical Systems, Coloplast, Johnson \& Johnson and GlaxoSmithKline.

\section{References}

1. Walsh PC, Donker PJ. Impotence following radical prostatectomy: insight into etiology and prevention. J Urol 1982;128:492-7.

2. Gontero $P$, Kirby R. Early rehabilitation of erectile function after nerve-sparing radical prostatectomy: What is the evidence? BJU Int 2004;93:916-8.

3. Mulhall JP, Morgentaler A. Penile rehabilitation should become the norm for radical prostatectomy patients. I Sex Med 2007;4:538-43.

4. Nandipati KC, Raina R, Agarwal A, et al. Erectile dysfunction following radical retropubic prostatectomy: epidemiology, pathophysiology and pharmacological management. Drugs Aging 2006;23:101-17.

5. Penson DF, Litwin MS. Quality of life after treatment for prostate cancer. Curr Urol Rep 2003:4:185-95

6. Burnett AL. Rationale for cavernous nerve restorative therapy to preserve erectile function after radical prostatectomy. Urology 2003;61:491-7.

7. Montorsi F, Briganti A, Salonia A, et al. Current and future strategies for preventing and managing erectile dysfunction following radical prostatectomy. Eur Urol 2004;45:123-33.

8. Leungwattanakii S, Bivalacqua TJ, Usta MF, et al. Cavernous neurotomy causes hypoxia and fibrosis in rat corpus cavernosum. J Androl 2003;24:239-45.

9. Daley JT, Watkins MT, Brown ML, et al. Prostanoid production in rabbit corpus cavernosum. II. Inhibition by oxidative stress. J Urol 1996;156:1169-73.

10. User HM, Hairston JH, Zelner DJ, et al. Penile weight and cell subtype specific changes in a postradical prostatectomy model of erectile dysfunction. J Urol 2003;169:1175-9.

11. Moreland RB. Is there a role of hypoxemia in penile fibrosis: a viewpoint presented to the Society for the Study of Impotence. Int I Impot Res 1998;10:113-20.

12. Mulhall JP, Slovick R, Hotaling J, et al. Erectile dysfunction after radical prostatectomy: hemodynamic profiles and their correlation with the recovery of erectile function. J Urol 2002;167:1371-5.

13. Zippe $C D$, Pahlajani $G$. Penile rehabilitation following radical prostatectomy: role of early intervention and chronic therapy. Urol Clin North Am 2007:34:601-18.
14. Mulhall JP. Penile rehabilitation following radical prostatectomy. Curr Opin Urol 2008; 18:613-20.

15. Mulhall JP, Muller A, Donohue JF, et al. The functional and structural consequences of cavernous nerve injury are ameliorated by sildenafil citrate. I Sex Med 2008;5:1126-36.

16. Ferrini MG, Davila HH, Kovanecz I, et al. Vardenafil prevents fibrosis and loss of corporal smooth muscle that occurs after bilateral cavernosal nerve resection in the rat. Urology 2006;68:429-35.

17. Vignozzi L, Filippi S, Morelli A, et al. Effect of chronic tadalafil administration on penile hypoxia induced by cavernous neurotomy in the rat. I Sex Med 2006;3:419-31.

18. Kovanecz I, Rambhatla A, Ferrini $M$, et al. Long-term continuous sildenafil treatment ameliorates corporal veno-occlusive dysfunction (CVOD) induced by cavernosal nerve resection in rats. Int I Impot Res 2008;20:202-12.

19. De Young $L X$, Domes $T$, Lim K, et al. Endothelial rehabilitation: the impact of chronic PDE5 inhibitors on erectile function and protein alterations in cavernous tissue of diabetic rats. Eur Urol 2008;54:213-20.

20. Muller A, Tal R, Donohue Jf, et al. The effect of hyperbaric oxygen therapy on erectile function recovery in a rat cavernous nerve injury model. J Sex Med 2008;5:562-70.

21. Montorsi F, Guazzoni G, Strambi LF, et al. Recovery of spontaneous erectile function after nerve-sparing radical retropubic prostatectomy with and without early intracavernous injections of alprostadil: results of a prospective, randomized trial. J Urol 1997;158:1408-10.

22. Mulhall J, Land $S$, Parker $M$, et al. The use of an erectogenic pharmacotherapy regimen following radical prostatectomy improves recovery of spontaneous erectile function. I Sex Med 2005;2:532-40

23. Brock $G$, Tu $L M$, Linet 01 . Return of spontaneous erection during long-term intracavernosal alprostadil (Caverject) treatment. Urology 2001;57:536-41.

24. Desouza C, Parulkar A, Lumpkin D, et al. Acute and prolonged effects of sildenafil on brachial artery flow-mediated dilatation in type 2 diabetes. Diabetes Care 2002;25:1336-9.

25. Schwartz EJ, Wong P, Graydon RJ. Sildenafil preserves intracorporeal smooth muscle after radical retropubic prostatectomy. J Urol 2004;171:771-4.

26. Padma-Nathan H, Guiliano F, Toler SM, et al. Postoperative nightly administration of sildenafil citrate significantly improves the return of normal spontaneous erectile function after bilateral nerve-sparing radical prostatectomy. J Urol 2003;169:375.

27. Padma-Nathan H, McCullough AR, Levine LA, et al. Randomized, double-blind, placebo-controlled study of postoperative nightly sildenafil citrate for the prevention of erectile dysfunction affer bilateral nerve-sparing radical prostatectomy. Int I Impot Res 2008;20:479-86

28. Montorsi F, Brock G, Lee J, et al. Effect of nightly versus on-demand vardenafil on recovery of erectile function in men following bilateral nerve-sparing radical prostatectomy. Eur Urol 2008:54:924-31.

29. Kohler TS, Pedro R, Hendlin K, et al. A pilot study on the early use of the vacuum erection device after radical retropubic prostatectomy. BJU Int 2007;100:858-62.

30. Raina R, Pahlajani G, Agarwal A, et al. The early use of transurethral alprostadil after radical prostatectomy potentially facilitates an earlier return of erectile function and successful sexual activity. BJU Int 2007;100:1317-21.

31. Marmar JL, DeBenedictis TJ, Praiss DE. The use of a vacuum constrictor device to augment a partial erection following an intracavernous injection. J Urol 1988; 140:975-9.

32. Yassin AA HA, Saad F. Favorable effects of early "penile rehabilitation" following nerve sparing radical prostatectomy. J Sex Med 2006;3:407.

33. Nandipati K, Raina R, Agarwal A, et al. Early combination therapy: intracavernosal injections and sildenafil following radical prostatectomy increases sexual activity and the return of natural erections. Int I Impot Res 2006;18:446-51.

Correspondence: Dr. Gerald Brock, Division of Urology, Department of Surgery, University of Western Ontario, 268 Grosvenor St., London ON N6A 4V2; gebrock@sympatico.ca 